\title{
The Levels of Vitamin D, Vitamin D Receptor, Homocysteine and Complex B Vitamin in Children with Autism Spectrum Disorders
}

\author{
Hatice Altun ${ }^{1}$, Ergül Belge Kurutaş ${ }^{2}$, Nilfer Şahin ${ }^{3}$, Olcay Güngörr ${ }^{4}$, Ebru Fındıklı ${ }^{5}$ \\ Departments of ${ }^{1}$ Child and Adolescent Psychiatry, ${ }^{2}$ Biochemistry, ${ }^{4}$ Pediatric Neurology, and ${ }^{5}$ Psychiatry, Faculty of Medicine, Kahramanmaras \\ Sutcu Imam University, Kahramanmaras, ${ }^{3}$ Department of Child and Adolescent Psychiatry, Faculty of Medicine, Muğla Sıtkı Koçman University, \\ Muğla, Turkey
}

\begin{abstract}
Objective: Autism spectrum disorder (ASD) is a complex neurodevelopmental syndrome with an increasingly prevalent etiology, yet not fully understood. It has been thought that vitamin D, complex B vitamin levels and homocysteine are associated with environmental factors and are important in ASD. The aim of this study was to examine serum vitamin D, vitamin D receptor (VDR), homocysteine, vitamin B6, vitamin B12 and folate levels in ASD.

Methods: In this study, serum vitamin D and VDR, homocysteine, vitamins B6, B12 and folate levels were determined in 60 patients with ASD (aged 3 to 12 years) and in 45 age-gender matched healthy controls. In addition, calcium, phosphorus and alkaline phosphatase, which are associated with vitamin D metabolism, were measured from serum in both groups. ASD severity was evaluted by the Childhood Autism Rating Scale (CARS).

Results: Serum vitamin D and VDR were substantially reduced in patients with ASD in comparision to control group. However, homocysteine level was significantly higher and vitamin B6, vitamin B12 and folate were also reduced in patients with ASD. Total CARS score showed a positive association with homocysteine and a negative correlation with vitamins D,B6, B12, folate and VDR.

Conclusion: This comprehensive study, which examines many parameters has shown that low serum levels of vitamins D, B6, B12, folate and VDR as well as high homocysteine are important in the etiopathogenesis of ASD. However, further studies are required to define the precise mechanism(s) of these parameters and their contributions to the etiology and treatment of ASD.
\end{abstract}

KEY WORDS: Autism spectrum disorder; Vitamin D; Vitamin D receptor; Homocysteine; Complex B vitamin.

\section{INTRODUCTION}

Autism spectrum disorder (ASD), a developmental disorder of the brain, has become increasingly prevalent in recent years. The etiopathogenesis negatively affects the lives of children through social emotional and behavioral. A numbers factor such as genetic, neurobiological, idiopathic, immunologic, environmental, prenatal, natal, and postnatal may have an important role in the etiology. ${ }^{1,2)}$

Received: May 4, 2017 / Revised: July 29, 2017

Accepted: August 1, 2017

Address for correspondence: Hatice Altun, MD

Department of Child and Adolescent Psychiatry, Faculty of

Medicine, Kahramanmaras Sutcu Imam University, Bat1

Çevreyolu Bulv., 251/A Onikişubat, Kahramanmaraş 46040,

Turkey

Tel: +90-3443003374, Fax: +90-3443003409

E-mail: drhaticealtun@gmail.com

ORCID: https://orcid.org/0000-0002-6802-8216
Numerous reports have described the etiology of ASD. In recent years, there has been a rapid increase in studies of vitamin $\mathrm{D}$ as an environmental factor in many medical diseases. Vitamin $\mathrm{D}$ has been shown to have effects on long-lasting skeletal and mineral metabolism. However, it has also been shown to have an effect on different systems such as the brain in recent years. ${ }^{3)}$ Therefore, vitamin D has been widely studied for its relationship to psychiatric diseases such as ASD, attention deficit hyperactivity disorder and schizophrenia. ${ }^{4-7)}$ It has been shown in several reports that vitamin $\mathrm{D}$ has a role in brain development and in numerous neuronal functions. It has been shown in animal studies that it has neurotrophic effect, neuroprotective effect, antioxidant effect, intracellular calcium regulation, effect on dopaminergic system, effect on neurotransmission and neuroplasticity, anti-inflammatory effect, cytokine regulation, changes in neurogenesis, apop-

(ㄷ) This is an Open-Access article distributed under the terms of the Creative Commons Attribution Non-Commercial License (http://creativecommons.org/licenses/by-nc/4.0) which permits unrestricted non-commercial use, distribution, and reproduction in any medium, provided the original work is properly cited. 
tosis and mitosis neuronal differentiation, structure, and metabolism. ${ }^{3,8,9)}$ Gestational or neonatal vitamin D deficiency has been associated with ASD as a developmental risk factor. ${ }^{10,11)}$ In addition, low serum vitamin D levels have been demonstrated to be decreased in ASD patients. ${ }^{6,72,13)}$ Other studies have reported that there is no change in levels of vitamin D and children ASD. ${ }^{14,15)}$ Vitamin $\mathrm{D}$ shows its effects by binding to vitamin $\mathrm{D}$ receptor (VDR). VDR is located in different tissues such as brain tissue and peripheral nerves. ${ }^{16)}$ According to our knowledge, there has been no study in the literature that has investigated the role of serum VDR levels in ASD.

Another subject considered as an environmental etiologic factor of ASD is homocysteine and vitamin B complexes. The amino acid, homocysteine, is produced during methionine metabolism in the body and is metabolised through two B-vitamin-dependent pathways transsulfuration to cysteine, or remethylation to methionine. ${ }^{17)}$ Therefore, vitamins B6 and B12, and folate are the basis for homocysteine metabolism. The use of certain drugs such as anticonvulsant, hypothyroidism, renal failure, methylene tetrahydrofolate reductase (MTHFR), cystathionine $\beta$-synthase and methionine synthase polymorphism may cause enhanced serum levels of homocysteine. ${ }^{18,19)}$ Furthermore, any defect of pathways from vitamins B6 and B12, and folate, which are important the breakdown of homocysteine, may lead to the accumulation of homocysteine in the body ${ }^{20}$ ) It has been shown that homocysteine, vitamins B6 and B12 and folate are important in various psychiatric disorders such as cognitive impairment, neurodegenerative diseases, schizophrenia and ASD. ${ }^{21-24)}$ High homocysteine levels have been previously reported to be associated with ASD. . $^{19,21,22,25)}$ Serum folate and vitamin B12 levels have been demonstrated to be decreased or normal in ASD patients. $14,21,25,26)$ However, the mechanism whereby homocysteine and these vitamin B complexes affect the etiopathogenesis of ASD remains unclear.

This study is a very comprehensive study, which examines many parameters. The goal of this report was to examine the serum vitamin $D$ and VDR, homocysteine, vitamin B6, vitamin B12 and folate levels in healthy individuals and compare to age and gender matched patients with ASD. In addition, serum calcium (Ca), phosphorus (P) and alkaline phosphatase (ALP) levels were associated with vitamin $\mathrm{D}$ metabolism and were measured in both groups. The relationship between these parameters and the Childhood Autism Rating Scale (CARS) total score assessing ASD severity was evaluated.

\section{METHODS}

\section{Patients}

There were 105 children enrolled in this study: 60 ASD patients (age, 3-12 years ; 52 male and 8 female); and 45 controls (age, 3-12 years; 36 male and 9 female). ASD was diagnosed using the Diagnostic and Statistical Manual of Mental Disorders, fourth edition, text revision (DSM-IV-TR) criteria. Using the expertise of a child neuropsychiatrist, participants were diagnosed with ASD. Any patient that was referred with genetic syndrome or any comorbid psychiatric (except mental retardation) and medical disorder, gastrointestinal problems, Cushing syndrome, anemia, metabolic disorders, neurological diseases, autoimmune disorders, and/or supplementation with vitamins and minerals (vitamin D, vitamin B6, folate or B1 2 containing preparations) in the last 6 months and/or drugs affecting vitamin D (e.g., steroids and anticonvulsant) were not included for this investigation. Children with no known neurodevelopmental, psychiatric, neurological disorder, infection, and/or no record of vitamins and mineral supplements were selected as healthy controls. These were age-, sex-, and/or season of blood collection-matched controls. CARS was performed by the researchers to determine ASD severity in the patient and control group through child observation and direct interviews with the family members. This is a well-established screening and classification method for children ASD and is consistent with DSM-IV-TR diagnostic criteria. CARS is comprised of fifteen items used to predict a score that defines ASD severity. A score greater than 30 but less than 36.5 is indicative of mild-to-moderate ASD, whereas a 37 to 60 score shows severe ASD. ${ }^{27)}$ For each patient, height and weight were recorded and the body mass index (BMI) was calculated. The research project was approved by the ethics committee of the Kahramanmaras Sutcu Imam University (No. 2014/03-15), and conformed to the provisions of the Declaration of Helsinki. Informed written consent was collected from each guardian or parent.

\section{Biochemical Measurements}

Venous blood was collected for measuring serum vita- 
Table 1. Characteristics of patients and healthy controls

\begin{tabular}{lccc}
\hline \multicolumn{1}{c}{ Characteristic } & ASD $(\mathrm{n}=60)$ & Controls $(\mathrm{n}=45)$ & $p$ value \\
\hline Age $(\mathrm{yr})$ & $5.8 \pm 2.7$ & $6.7 \pm 2.5$ & 0.092 \\
Gender, male/ female & $52 / 8$ & $36 / 9$ & 0.359 \\
CARS total score & $42.3 \pm 7.46(30-60)$ & $15.9 \pm 1.02(15-18)$ & 0.000 \\
Body mass index $\left(\mathrm{kg} / \mathrm{m}^{2}\right)$ & $18.6 \pm 2.8$ & $19.6 \pm 2.5$ & 0.461 \\
\hline
\end{tabular}

Values are presented as mean \pm standard deviation (range) or number only.

ASD, autism spectrum disorder.

Table 2. Laboratory results of patients and healthy controls

\begin{tabular}{lccc}
\hline \multicolumn{1}{c}{ Variable } & ASD $(\mathrm{n}=60)$ & Controls $(\mathrm{n}=45)$ & $p$ value \\
\hline Vitamin D $(\mathrm{ng} / \mathrm{ml})$ & $13.79 \pm 1.03^{*}$ & $16.58 \pm 1.06$ & $<0.001$ \\
Vitamin D receptor $(\mathrm{ng} / \mathrm{ml})$ & $1.24 \pm 0.11^{*}$ & $1.92 \pm 0.26$ & $<0.001$ \\
Homosistein $(\mu \mathrm{mol} / \mathrm{L})$ & $8.90 \pm 0.19^{\dagger}$ & $7.46 \pm 0.21$ & $<0.001$ \\
Vitamin B6 $(\mathrm{ng} / \mathrm{ml})$ & $25.17 \pm 3.64^{*}$ & $53.06 \pm 7.95$ & $<0.001$ \\
Folate $(\mathrm{pg} / \mathrm{ml})$ & $121.16 \pm 8.04^{*}$ & $172.31 \pm 17.19$ & $<0.001$ \\
Vitamin B12 $(\mathrm{pg} / \mathrm{ml})$ & $181.5 \pm 41.61^{*}$ & $382.06 \pm 71.34$ & $<0.001$ \\
Calcium $(\mathrm{mg} / \mathrm{dl})$ & $9.7 \pm 0.5$ & $9.4 \pm 0.7$ & $>0.05$ \\
Phosphorus $(\mathrm{mg} / \mathrm{dl})$ & $5.1 \pm 1.1$ & $5.0 \pm 0.5$ & $>0.05$ \\
ALP $(\mathrm{U} / \mathrm{L})$ & $192.4 \pm 57.1$ & $193.1 \pm 61.1$ & $>0.05$ \\
\hline
\end{tabular}

Values are presented as mean \pm standard deviation.

ASD, autism spectrum disorders; ALP, alkaline phosphatase.

*Lower than those of controls, ${ }^{\dagger}$ higher than those of controls.

min D, VDR, homosisteine, vitamin B6 and B12, folate, $\mathrm{Ca}, \mathrm{P}$ and ALP, between 8:00 and 10:00 AM. The serum were collected and put in the $-20^{\circ} \mathrm{C}$ until analysis. All patients were examined between March and September so vitamin $\mathrm{D}$ deficiency in the winter time would not be a factor.

Vitamin D, VDR, homocysteine, vitamins B6 and B12, folate levels in samples were analyzed by using a enzyme immunoassay technique (ELISA). Ca, P, and ALP were analyzed using the automated standard spectrophotometric laboratory method.

\section{Statistical Analysis}

The parametric data were shown as mean \pm standard deviation. The $t$ test and chi-square test were used for differences between two groups. Pearson's correlation test was used to evaluate associations for continuous variables. A $p$ value of less than 0.05 was accepted as significant. IBM Statistical Package for Social Sciences software (version 22; IBM Co., Armonk, NY, USA) was used for statistical analyses.

\section{RESULTS}

The mean age of the ASD $(n=60)$ and healthy controls $(n=45)$ was $5.8 \pm 2.7$ years and $6.7 \pm 2.5$ years, respectively. No differences were found between the groups in terms of age, gender, weight, height, and BMI (all $p>0.05$ ) (Table 1 ). In addition, no differences in birth seasons or seasons of blood collection were found.

The mean serum vitamin D levels in the ASD and control groups were $13.79 \pm 1.03 \mathrm{ng} / \mathrm{ml}$ and $16.58 \pm 1.06$ $\mathrm{ng} / \mathrm{ml}$ (mean \pm standard deviation), which was statistically significant $(p<0.001)$. The serum VDR levels were statistically significant and reduced in children ASD compared to healthy controls $(1.24 \pm 0.11 \mathrm{ng} / \mathrm{ml}$ and $1.92 \pm 0.26 \mathrm{ng} / \mathrm{ml}$, respectively; $p<0.001$ ) (Table 2 ).

Homocysteine levels were significantly increased for patients with ASD in comparison to the control group $(8.90 \pm 0.19 \mu \mathrm{mol} / \mathrm{L}$ and $7.46 \pm 0.21 \mu \mathrm{mol} / \mathrm{L}$, respectively; $p$ $<0.001)$. The levels of vitamin B6, folate, vitamin B12, were found significantly lower in the patients with ASD $(25.17 \pm 3.64 \mathrm{ng} / \mathrm{ml}, 121.16 \pm 8.04 \mathrm{pg} / \mathrm{ml}$, and $181.5 \pm 41.61$ $\mathrm{pg} / \mathrm{ml}$, respectively; $53.06 \pm 7.95 \mathrm{ng} / \mathrm{ml}, 172.31 \pm 17.19$ $\mathrm{pg} / \mathrm{ml}$, and $382.06 \pm 71.34 \mathrm{pg} / \mathrm{ml}$, respectively; $p<0.001$ ) 
Table 3. Correlation levels between CARS total score and age and vitamin D, vitamin D receptor, vitamin B6, folate and vitamin B12

\begin{tabular}{cccccc}
\hline & Vitamin D & Vitamin D receptor & Homocysteine & Vitamin B6 & Folate \\
\hline CARS & & & & \\
$r$ & $-0.687^{*}$ & $-0.797^{*}$ & $0.688^{*}$ & $-0.833^{*}$ & $-0.840^{*}$ \\
$p$ & 0.000 & 0.000 & 0.000 & 0.000 & 0.000 \\
Age & & & & $0.794^{*}$ & 0.149 \\
$r$ & $0.296^{*}$ & 0.179 & -0.081 & 0.107 & 0.153 \\
$p$ & 0.002 & 0.068 & 0.412 & 0.279 & 0.120 \\
\hline
\end{tabular}

CARS, Childhood Autism Rating Scale.

*Correlation is significant at the 0.01 level (2-tailed).

(Table 2).

In the ASD and control groups, mean serum Ca was $9.7 \pm 0.5 \mathrm{mg} / \mathrm{dl}$ and $9.4 \pm 0.7 \mathrm{mg} / \mathrm{dl}$, P was $5.1 \pm 1.1 \mathrm{mg} / \mathrm{dl}$ and $5.0 \pm 0.5 \mathrm{mg} / \mathrm{dl}$, and ALP was $192.4 \pm 57.1 \mathrm{U} / \mathrm{L}$ and $193.1 \pm 61.1 \mathrm{U} / \mathrm{L}$, respectively. The mean levels of these parameters were not different significantly for the groups (all $p>0.05$ ) (Table 2).

CARS total scores of patients were significantly increased compared to healthy controls, with means of $42.3 \pm 7.46$ and $15.9 \pm 1.02$, respectively $(p=0.000)$ (Table 1).

There was a positive association for homocysteine levels and negative association between vitamin $D, V D R$, vitamin B6, folate and vitamin B12 levels according to CARS total scores (Table 3). In addition, vitamin D and homocysteine levels had a negative association, while there was a positive association between age, VDR, vitamin B6, folate and vitamin B12. There was a negative correlation between VDR level and homocysteine and a positive correlation was found between other vitamins.

\section{DISCUSSION}

In this study, serum vitamin D and VDR levels were significantly reduced in children ASD compared to the healthy controls. This finding supports the previous studies in which vitamin $\mathrm{D}$ was reported to be low in ASD. ${ }^{6,7,12,13,28-30)}$ Kočovská et al. ${ }^{29)}$ demonstrated that ASD patients had lower ${ }^{25}(\mathrm{OH}) \mathrm{D}$ levels compared to siblings, parents, and healthy controls. Interestingly, Gong and colleagues demonstrated an increased amount of ASD children with ${ }^{25}(\mathrm{OH}) \mathrm{D}$ levels $<50 \mathrm{nmol} / \mathrm{L}$ compared to controls ( $58 \%$ vs. $33 \%$ respectively; $p=0.01$ ) when examination of both cases and controls for autistic-like features was taken into account. ${ }^{6)}$ Recently, Feng et al.. ${ }^{31)}$ reported an increased amount of ASD children with ${ }^{25}(\mathrm{OH})$ D levels $<$ $25 \mathrm{nmol} / \mathrm{L}(13 \%$ vs. $0 \% ; p=0.03)$ and $<75 \mathrm{nmol} / \mathrm{L}(71 \%$ vs. $62 \% ; p=0.03$ ) than controls. Contrary to these studies, there are studies showing that there is no difference in vitamin D levels in ASD. ${ }^{14,15)}$ Adams and colleagues showed significant differences statistically for biomarkers indicative of increased oxidative damage. In addition, they showed that there was a reduced capacity for detoxification and energy transport and vitamin deficiency children with ASD compared to controls. Interestingly, plasma ${ }^{25}(\mathrm{OH}) \mathrm{D}$ was not different between groups. ${ }^{15)}$

In our study, blood was collected during the marchseptember months to avoid seasonal variations in vitamin D levels in patients with ASD. Similarly, in some studies blood samples from ASD and healthy children were collected during the summer months. Similar to our study, children with ASD had reduced vitamin D compared to controls. At the same time, reports showed that there was no difference in patients with ASD and control groups in terms of the birth season in these studies. ${ }^{12,13,30)}$ In our report, no difference for the birth season was reported.

Although children with ASD are exposed to less sunlight due to low outdoor activity and sedentary behavior, insufficient levels of vitamin D due to repetitive and restricted dietary behaviors are thought to be responsible for the vitamin D deficiency in children with ASD compared to healthy children, the exact mechanism of vitamin D deficiency is unknown. ${ }^{32-34)}$

Low vitamin $\mathrm{D}$ has been determined in the pathogenesis of ASD in various ways. It has been described that ASD is both an organ specific and systematic abnormalities such as de-novogene mutations, oxidative stress, impaired detoxification system, inflammation, immune dysregulation, abnormal neurotrophic factor and neurotransmitter levels. ${ }^{35,36)}$ Even though aforementioned facts 
may be associated with vitamin D deficiency, the mechanism in ASD children still needs further validation.

Vitamin D shows its effects by binding to VDR. VDR is found in many different tissues such as brain tissue and peripheral nerves. The VDR gene has important roles in bone mineralization and vitamin D metabolism. It has been shown that the mutations related to this gene may inhibit vitamin $\mathrm{D}$ metabolism and cause neurodevelopmental disorders, although serum $\mathrm{Ca}, \mathrm{P}$, and parathormone levels are within normal limits. There are studies reporting that there is a relationship between VDR gene polymorphism and ASD. ${ }^{16,37,38)}$ In our study, it was determined that serum VDR levels were reduced children with ASD in comparison to controls. According to our knowledge, no studies have been done to evaluate serum VDR in ASD. It is thought that low VDR levels may affect ASD independently of vitamin D levels. However, this study is the first to determine the level of serum VDR. Therefore, there is a need for studies evaluating the relationship between VDR and ASD.

As another finding of our study, patients with ASD were found to have higher serum homocysteine levels and lower levels of vitamin B6, folate, and vitamin B12 compared to control group. Homocysteine is a sulfur-containing amino acid that has been demonstrated for its role in the pathogenesis of many diseases. ${ }^{39)}$ Recent studies have demonstrated that homocysteine levels are increased in children with ASD when compared to healthy children in a variety of biological fluids such as serum, plasma, and urine. $^{19,21,22,25)}$

Homocysteine is a powerful excitotoxin, and its metabolism products cause protein damage and structural changes, which generate toxic proteins and induce an autoimmune response. ${ }^{40)}$ Several studies on the neurotoxicity of homocysteine indicate that homocysteine can induce neuronal damage causing activation of $N$-methyl-D-aspartate (NMDA) receptors and cell loss through excitotoxicity as well as apoptosis. ${ }^{41-43)}$ However, the exact mechanism of the relationship between ASD and homocysteine is still unclear.

In our study, it was found that vitamin B6, one of the vitamins serving as a cofactor in serum homocysteine metabolism, was lower in children ASD in comparison to controls. Vitamin B6 has been studied less in ASD compared to folate and vitamin B12. However, there are previous studies which show that B6-Mg treatments that cause indueing vitamin B6 levels and ASD symptoms in children with ASD. ${ }^{44)}$

We observed a reduction in folate serum levels for children ASD than controls in the current study. However, Uğur and Gürkan ${ }^{14)}$ did not observed any changes in folate levels between ASD and healthy controls. Nevertheless, other reports were consistent with our results in regards to the reduction of folate in ASD children. ${ }^{25,26)}$ Folate is important for neural development and is a coenzyme for 'one-carbon' metabolic pathway which is utilized in a number of processes including DNA synthesis and regulation, cell proliferation, and immune function. ${ }^{45,46)}$ It is also important in the realization and regulation of many neurological events, such as DNA damage repair, monoamine synthesis and the synthesis of transmitters in the central nervous system. Folate is an essential metabolite involved in almost all methylation reactions in the body. Folate insufficiency can affect cellular function including methylation and redox homeostasis, which contribute to ASD pathology. ${ }^{40)}$ Also, the folate deficiency during pregnancy has been reported as a risk for offspring developing ASD. ${ }^{47)}$ Schmidt et al. ${ }^{48)}$ showed that mothers of children with ASD ingested low amounts of folate during gestation. In contrast, other studies showed that mothers of autistic children had folate supplementation in pregnancy and consume elevated amounts of the nutrient. ${ }^{26)}$

We found lower vitamin B12 serum levels in children ASD compared to controls in our study. This finding supports the studies showing low serum vitamin B12 levels in ASD patients. ${ }^{25,26)}$ A reduction in B12 is expected to block transmethylation of homocysteine to methionine resulting in increased homocysteine levels and decreasing indispensable methylation reactions of proteins, phospholipids, DNA, and neurotransmitters. Such diminished methylation may affect the development of the nervous system by interfering with myelogenesis. ${ }^{49)}$

Evidence has demonstrated that children with ASD eat selectively. Improper diet, substantial food selectivity, and/or gastrointestinal problems cause reduced dietary intake and micronutrient complications. ${ }^{33,50,51)}$ According to the studies conducted by Xia et al., ${ }^{52)}$ dietary habits of autistic children shows that most of them had inadequate intake of folate, vitamins B6, A, C, and zinc. A reduction in folate levels and $B$ vitamins are inversely proportional to the levels of homocysteine and some autistic symptoms. ${ }^{511}$ According to the results of a study by 
Kałużna-Czaplińska et al. ${ }^{53)}$ found that high levels of urinary homocysteine were found in children ASD. Supplementation of diets on ASD children with vitamins B6, B12, and folate was more effective compare to supplementation of diets only with vitamin B6 and B12 to lower urinary homocysteine level. Similar results were supported by the study made by Ali et $a / .^{25)}$ that blood homocysteine levels lowered by supplemental treatment of vitamins B6, B12, and folate.

Feeding difficulties in ASD can be alleviated through the supplementation of essential nutrients such as vitamins B6, folate and vitamin B12, which has been recommended by some studies. ${ }^{54)}$ The importance of vita$\mathrm{min} /$ mineral supplements in children ASD has been shown. This possibly improves their performance in the areas of hyperactivity, tantrums, overall behavior, and receptive language. ${ }^{55)}$ Additionally, folate adminstration in autistic children with low 5MTHF (L-5-methyltetrahydrofolate) levels has been found to result in normalization of folate, and to relieve ASD symptoms. ${ }^{56)}$ However, reports about consumption and concentration of vitamins in children ASD are still inconclusive. ${ }^{57)}$

In our study, there was a statistically significant negative association between ASD and serum vitamin $D$ and VDR, vitamin B6 and B12, and folate according to the total CARS scores. In addition, a positive association with homocysteine was shown. High serum homocysteine with low levels of serum vitamin D, VDR and B6, folate, vitamin $\mathrm{B} 12$ are associated with more severe ASD clinical findings. This finding supports the studies showing negative correlation with previous CARS scores. ${ }^{6,13,30)}$ There was no significant correlation between CARS score and age, Ca, P, ALP, BMI. A significant positive correlation between age and vitamin $D$ levels only was determined. It was found a relationship in our study between high homocysteine levels with low serum vitamin D, VDR and B6, folate, and vitamin B12. This finding supports the studies showing that low levels of vitamins B6 and B12 and folate associated with increased levels of homocysteine in the literature. Low vitamin D and VDR levels may cause a rise in homocysteine levels and may also have a role in the etiology of ASD. However, this is the first study to investigate the association between homocysteine and vitamin D and VDR, there is a need for further studies to evaluate this relationship in more detail.

This study has some limitations. It is a cross-sectional investigation, which was conducted in a small sample group, and the study samples were not assessed for mean sun exposure and oral diet habits. In this study, psychiatric comorbidities were not assessed using semi-structured instruments such as the Schedule for Affective Disorders and Schizophrenia for School-Age ChildrenPresent and Lifetime Version (K-SADS-PL). In addition, gene polymorphisms such as MTHFR and central nervous system associated with folate and homocysteine metabolism were not assayed.

This study has shown that low serum vitamin $\mathrm{D}$ and VDR levels and high homocysteine and low vitamins B6 and B12 and folate may be important in the etiopathogenesis of ASD. It is the first study determining VDR levels in ASD and evaluating the relation between ASD and VDR; however, further studies should be done to determine the exact mechanism of contribution of these parameters to ASD etiology and treatment. Also, a larger controlled study for assessing serum levels of vitamin D, vitamin B6, folate, vitamin B12 intake in ASD patients is warranted. The effects of these vitamin complexes on clinical symptoms in individuals with ASD, and optimal supplementation strategies and their long-term effects on child neurodevelopment also needs further investigation.

\section{- Acknowledgments}

This study was supported by Kahramanmaras Sutcu Imam University Research Foundation (2014/3-49M). The authors wish to thank the patients and families who participated in this study.

\section{REFERENCES}

1. Cannell JJ. On the aetiology of autism. Acta Paediatr 2010;99: 1128-1130.

2. Kinney DK, Barch DH, Chayka B, Napoleon S, Munir KM. Environmental risk factors for autism: do they help cause de novo genetic mutations that contribute to the disorder? Med Hypotheses 2010;74:102-106.

3. Ucuz II, Dursun OB, Aydin N. The effects of vitamin D3 on brain development and autism. Klinik Psikofarmakol Bulteni 2015:25:302-311.

4. Goksugur SB, Tufan AE, Semiz M, Gunes C, Bekdas M, Tosun $\mathrm{M}$, et al. Vitamin $D$ status in children with attention-deficit-hyperactivity disorder. Pediatr Int 2014;56:515-519.

5. Itzhaky D, Amital D, Gorden K, Bogomolni A, Arnson Y, Amital $\mathrm{H}$. Low serum vitamin $D$ concentrations in patients with schizophrenia. Isr Med Assoc J 2012;14:88-92.

6. Gong ZL, Luo CM, Wang L, Shen L, Wei F, Tong RJ, et al. 
Serum 25-hydroxyvitamin D levels in Chinese children with autism spectrum disorders. Neuroreport 2014;25:23-27.

7. Humble MB, Gustafsson S, Bejerot S. Low serum levels of 25-hydroxyvitamin D (25-OHD) among psychiatric out-patients in Sweden: relations with season, age, ethnic origin and psychiatric diagnosis. J Steroid Biochem Mol Biol 2010;121: 467-470.

8. Eyles D, Burne T, McGrath J. Vitamin D in fetal brain development. Semin Cell Dev Biol 2011;22:629-636.

9. Harms LR, Burne TH, Eyles DW, McGrath JJ. Vitamin D and the brain. Best Pract Res Clin Endocrinol Metab 2011;25:657669.

10. Grant WB, Soles CM. Epidemiologic evidence supporting the role of maternal vitamin $D$ deficiency as a risk factor for the development of infantile autism. Dermatoendocrinol 2009; $:$ 223-228.

11. Cannell JJ, Hollis BW. Use of vitamin D in clinical practice. Altern Med Rev 2008;13:6-20.

12. Meguid NA, Hashish AF, Anwar M, Sidhom G. Reduced serum levels of 25-hydroxy and 1,25-dihydroxy vitamin $D$ in Egyptian children with autism. I Altern Complement Med 2010;16:641-645.

13. Mostafa GA, Al-Ayadhi LY. Reduced serum concentrations of 25-hydroxy vitamin $D$ in children with autism: relation to autoimmunity. J Neuroinflammation 2012;9:201.

14. Uğur Ç, Gürkan CK. Serum vitamin D and folate levels in children with autism spectrum disorders. Res Autism Spectr Disord 2014;8:1641-1647.

15. Adams JB, Audhya T, McDonough-Means S, Rubin RA, Quig D, Geis E, et al. Nutritional and metabolic status of children with autism vs. neurotypical children, and the association with autism severity. Nutr Metab (Lond) 2011;8:34.

16. Goltzman D, Hendy GN, White JH. Vitamin D and its receptor during late development. Biochim Biophys Acta 2015;1849: 171-180.

17. Perła-Kaján J, Twardowski T, Jakubowski H. Mechanisms of homocysteine toxicity in humans. Amino Acids 2007;32:561572

18. Malinowska J, Kolodziejczyk J, Olas B. The disturbance of hemostasis induced by hyperhomocysteinemia; the role of antioxidants. Acta Biochim Pol 2012;59:185-194.

19. Kałużna-Czaplińska J, Żurawicz E, Michalska M, Rynkowski J. A focus on homocysteine in autism. Acta Biochim Pol 2013;60:137-142.

20. Herrmann W, Herrmann M, Obeid R. Hyperhomocysteinaemia: a critical review of old and new aspects. Curr Drug Metab 2007;8:17-31.

21. Paşca SP, Nemeş B, Vlase L, Gagyi CE, Dronca E, Miu AC, et al. High levels of homocysteine and low serum paraoxonase 1 arylesterase activity in children with autism. Life Sci 2006; 78:2244-2248.

22. Kałużna-Czaplińska J, Michalska M, Rynkowski J. Homocysteine level in urine of autistic and healthy children. Acta
Biochim Pol 2011,58:31-34.

23. Stanger O, Fowler B, Piertzik K, Huemer M, Haschke-Becher E, Semmler A, et al. Homocysteine, folate and vitamin B12 in neuropsychiatric diseases: review and treatment recommendations. Expert Rev Neurother 2009;9:1393-1412.

24. McMahon JA, Green TJ, Skeaff CM, Knight RG, Mann JI, Williams SM. A controlled trial of homocysteine lowering and cognitive performance. N Eng/ J Med 2006;354:2764-2772.

25. Ali A, Waly MI, Al-Farsi YM, Essa MM, Al-Sharbati MM, Deth RC. Hyperhomocysteinemia among Omani autistic children: a case-control study. Acta Biochim Pol 2011;58:547-551.

26. Al-Farsi YM, Waly MI, Deth RC, Al-Sharbati MM, Al-Shafaee $\mathrm{M}, \mathrm{Al}$-Farsi $\mathrm{O}$, et al. Low folate and vitamin $B 12$ nourishment is common in Omani children with newly diagnosed autism. Nutrition 2013;29:537-541.

27. Sucuoglu B, Oktem F, Akkok F, Gokler B. [A study of the scales for the assessment of the children with autism]. I Psychiatry Psychol Psychopharmacol 1996;4:116-121. Turkish.

28. Fernell E, Bejerot S, Westerlund J, Miniscalco C, Simila H, Eyles D, et al. Autism spectrum disorder and low vitamin D at birth: a sibling control study. Mol Autism 2015;6:3.

29. Kočovská E, Andorsdóttir G, Weihe P, Halling J, Fernell E, Stóra $\mathrm{T}$, et al. Vitamin $d$ in the general population of young adults with autism in the Faroe Islands. J Autism Dev Disord 2014;44:2996-3005.

30. Saad K, Abdel-Rahman AA, Elserogy YM, Al-Atram AA, Cannell JJ, Bjørklund G, et al. Vitamin D status in autism spectrum disorders and the efficacy of vitamin D supplementation in autistic children. Nutr Neurosci 2016;19:346-351.

31. Feng J, Shan L, Du L, Wang B, Li H, Wang W, et al. Clinical improvement following vitamin D3 supplementation in autism spectrum disorder. Nutr Neurosci 2017;20:284-290.

32. Must A, Phillips SM, Curtin C, Anderson SE, Maslin M, Lividini $\mathrm{K}$, et al. Comparison of sedentary behaviors between children with autism spectrum disorders and typically developing children. Autism 2014;18:376-384.

33. Marí-Bauset S, Llopis-González A, Zazpe-García I, Marí-Sanchis A, Morales-Suárez-Varela M. Nutritional status of children with autism spectrum disorders (ASDs): a case-control study. J Autism Dev Disord 2015;45:203-212.

34. Emond A, Emmett P, Steer C, Golding J. Feeding symptoms, dietary patterns, and growth in young children with autism spectrum disorders. Pediatrics 2010;126:e337-e342.

35. Rossignol DA, Frye RE. Evidence linking oxidative stress, mitochondrial dysfunction, and inflammation in the brain of individuals with autism. Front Physiol 2014,5:150.

36. Groves NJ, McGrath JJ, Burne TH. Vitamin D as a neurosteroid affecting the developing and adult brain. Annu Rev Nutr 2014; 34:117-141.

37. Coşkun S, Şimşek Ş, Camkurt MA, Çim A, Çelik SB. Association of polymorphisms in the vitamin $D$ receptor gene and serum 25-hydroxyvitamin D levels in children with autism spectrum disorder. Gene 2016;588:109-114. 
38. Yan J, Feng J, Craddock N, Jones IR, Cook EH Jr, Goldman D, et al. Vitamin D receptor variants in 192 patients with schizophrenia and other psychiatric diseases. Neurosci Lett 2005; 380:37-41.

39. Newton LA, Sandhu K, Livingstone C, Leslie R, Davis J. Clinical diagnostics for homocysteine: a rogue amino acid? Expert Rev Mol Diagn 2010;10:489-500.

40. Mattson MP, Shea TB. Folate and homocysteine metabolism in neural plasticity and neurodegenerative disorders. Trends Neurosci 2003;26:137-146.

41. Ho PI, Ortiz D, Rogers E, Shea TB. Multiple aspects of homocysteine neurotoxicity: g/utamate excitotoxicity, kinase hyperactivation and DNA damage. J Neurosci Res 2002;70:694702.

42. Lipton SA, Kim WK, Choi YB, Kumar S, D'Emilia DM, Rayudu $\mathrm{PV}$, et al. Neurotoxicity associated with dual actions of homocysteine at the N-methyl-D-aspartate receptor. Proc Natl Acad Sci U S A 1997; 94:5923-5928.

43. Kruman II, Culmsee C, Chan SL, Kruman Y, Guo Z, Penix L, et al. Homocysteine elicits a DNA damage response in neurons that promotes apoptosis and hypersensitivity to excitotoxicity. J Neurosci 2000;20:6920-6926.

44. Nye C, Brice A. Combined vitamin B6-magnesium treatment in autism spectrum disorder. Cochrane Database Syst Rev 2005; (4):CD003497.

45. Desai A, Sequeira JM, Quadros EV. The metabolic basis for developmental disorders due to defective folate transport. Biochimie 2016;126:31-42.

46. Kennedy DO. B Vitamins and the brain: mechanisms, dose and efficacy--a review. Nutrients 2016;8:68.

47. Fujiwara T, Morisaki N, Honda Y, Sampei M, Tani Y. Chemicals, nutrition, and autism spectrum disorder: a minireview. Front Neurosci 2016;10:174.

48. Schmidt RJ, Tancredi DJ, Ozonoff S, Hansen RL, Hartiala J, Allayee $\mathrm{H}$, et al. Maternal periconceptional folic acid intake and risk of autism spectrum disorders and developmental delay in the CHARGE (CHildhood Autism Risks from Genetics and Environment) case-control study. Am J Clin Nutr 2012;96: 80-89.

49. Moretti R, Torre P, Antonello RM, Cattaruzza T, Cazzato G, Bava A. Vitamin B12 and folate depletion in cognition: a review. Neurol India 2004;52:310-318.

50. Fulceri F, Morelli M, Santocchi E, Cena H, Del Bianco T, Narzisi A, et al. Gastrointestinal symptoms and behavioral problems in preschoolers with autism spectrum disorder. Dig Liver Dis 2016;48:248-254.

51. Williams KE, Gibbons BG, Schreck KA. Comparing selective eaters with and without developmental disabilities. J Dev Phys Disabil 2005;17:299-309.

52. Xia W, Zhou Y, Sun C, Wang J, Wu L. A preliminary study on nutritional status and intake in Chinese children with autism. Eur J Pediatr 2010;169:1201-1206.

53. Kałużna-Czaplińska J, Michalska M, Rynkowski J. Vitamin supplementation reduces the level of homocysteine in the urine of autistic children. Nutr Res 2011;31:318-321.

54. Hjiej H, Doyen C, Couprie C, Kaye K, Contejean Y. [Substitutive and dietetic approaches in childhood autistic disorder: interests and limits]. Encephale 2008;34:496-503. French.

55. Adams JB, Audhya T, McDonough-Means S, Rubin RA, Quig $\mathrm{D}$, Geis $\mathrm{E}$, et al. Effect of a vitamin/mineral supplement on children and adults with autism. BMC Pediatr 2011;11:111.

56. Ramaekers VT, Blau N, Sequeira JM, Nassogne MC, Quadros EV. Folate receptor autoimmunity and cerebral folate deficiency in low-functioning autism with neurological deficits. Neuropediatrics 2007;38:276-281.

57. Castro K, Klein Lda S, Baronio D, Gottfried C, Riesgo R, Perry IS. Folic acid and autism: what do we know? Nutr Neurosci 2016;19:310-317. 